\title{
Human plasma enhances the expression of Staphylococcal microbial surface components recognizing adhesive matrix molecules promoting biofilm formation and increases antimicrobial tolerance In Vitro
}

\author{
Anthony P Cardile ${ }^{1 *}$, Carlos J Sanchez Jr. ${ }^{2}$, Meghan E Samberg ${ }^{2}$, Desiree R Romano ${ }^{2}$, Sharanda K Hardy², \\ Joseph C Wenke ${ }^{2}$, Clinton K Murray ${ }^{1}$ and Kevin S Akers ${ }^{1,2}$
}

\begin{abstract}
Background: Microbial biofilms have been associated with the development of chronic human infections and represent a clinical challenge given their increased antimicrobial tolerance. Staphylococcus aureus is a major human pathogen causing a diverse range of diseases, of which biofilms are often involved. Staphylococcal attachment and the formation of biofilms have been shown to be facilitated by host factors that accumulate on surfaces. To better understand how host factors enhance staphylococcal biofilm formation, we evaluated the effect of whole human plasma on biofilm formation in clinical isolates of $S$. aureus and the expression of seven microbial surface components recognizing adhesive matrix molecules (MSCRAMMs) known to be involved in biofilm formation by quantitative real-time PCR. We also evaluated whether plasma augmented changes in S. aureus biofilm morphology and antimicrobial resistance.

Results: Exposure of clinical isolates of S. aureus to human plasma (10\%) within media, and to a lesser extent when coated onto plates, significantly enhanced biofilm formation in all of the clinical isolates tested. Compared to biofilms grown under non-supplemented conditions, plasma-augmented biofilms displayed significant changes in both the biofilm phenotype and cell morphology as determined by confocal scanning laser microscopy (CLSM) and scanning electron microscopy (SEM), respectively. Exposure of bacteria to plasma resulted in a significant fold-increase in MSCRAMM expression in both a time and isolate-dependent manner. Additionally, plasma-augmented biofilms displayed an increased tolerance to vancomycin compared to biofilms grown in non-supplemented media.

Conclusions: Collectively, these studies support previous findings demonstrating a role for host factors in biofilm formation and provide further insight into how plasma, a preferred growth medium for staphylococcal biofilm formation enhances as well as augments other intrinsic properties of $S$. aureus biofilms. Consequently, these findings indicate that incorporation of host factors may be necessary to better replicate in vivo conditions and for the best utility of a clinical biofilm assay to evaluate the process of biofilm formation and treatments.
\end{abstract}

Keywords: Human plasma, Biofilm, Staphylococcus aureus, Microbial surface components recognizing adhesive matrix molecules (MSCRAMMs), Vancomycin

\footnotetext{
* Correspondence: anthony.p.cardile.mil@mail.mil

'Department of Medicine, Infectious Disease Service, Brooke Army Medical

Center, 3551 Roger Brooke Drive, JBSA Fort Sam Houston, TX 78234, USA

Full list of author information is available at the end of the article
} 


\section{Background}

Staphylococcus aureus is a significant human pathogen that causes a wide range of infections. The ability of $S$. aureus to colonize and establish biofilms, a surfaceattached microbial community surrounded by a selfproduced polymeric matrix, is a central pathogenic event contributing to disease in humans [1]. Biofilms are implicated as a significant factor contributing to chronic human infections [2-4], and represent a major challenge to modern medicine given their recalcitrance to antimicrobials and host mechanisms of clearance. Biofilm formation is a complex process involving distinct phases of attachment, accumulation, and maturation. The attachment of staphylococci and subsequently the accumulation phases of biofilm development are predominantly mediated by different types of bacterial adhesins. More specifically, a class of surface proteins known as the microbial surface components recognizing adhesive matrix molecules (MSCRAMMs), which in addition to virulence, are responsible for mediating initial attachment to both naïve tissues and various biomaterials [5-7].

Data continues to accumulate regarding S. aureus biofilm formation, but there is increasing evidence that in vitro biofilm assays may not accurately represent in vivo biofilms [8]. Factors potentially causing discrepancies between in vivo and in vitro conditions include the presence of host proteins, of which human plasma is the best characterized [5-9]. Plasma is a major component of blood [normally approximating 55\%, volume/ volume $(\mathrm{v} / \mathrm{v})]$ and is composed of coagulation factors, albumin, globulins and other factors [9-11]. Most body fluids consist of plasma filtrates and proteins present in plasma are also found at varying concentrations in human body fluids, to include (percent, v/v): burn wound exudates (10-44\%), acute soft tissue wound exudates (23-36\%), interstitial fluid (10-27\%), nasal secretions (15-45\%), ascitic fluid (4-26\%), lymphatic fluid (10-50\%), and synovial fluid (1-73\%) [12-17]. The importance of host proteins in facilitating biofilm formation is highlighted by studies demonstrating that medical implants are often coated by various host matrix proteins, serving to enhance bacterial attachment and biofilm formation in vivo $[7,8]$ as well as in vitro where the use of plasma has been shown to promote biofilm growth $[18,19]$.

To better understand how host factors, in particular those within human plasma, augment biofilm formation in $S$. aureus, herein we examined the effect of human plasma on biofilm formation in clinical isolates, and evaluated its effects on the expression of staphylococcal MSCRAMMs important to biofilm formation. Furthermore, we also evaluated the effects of plasma on biofilm/bacterial morphology and changes in resistance to antimicrobials.

\section{Results and discussion}

Human plasma enhances biofilm formation by clinical isolates of S. aureus, in part through increased MSCRAMM expression

Previous studies have shown that supplementing media, as well as coating surfaces, with human plasma can facilitate $S$. aureus attachment and promote biofilm accumulation in vitro $[18,19]$. Consistent with these studies, supplementation of media with plasma, and to a much lesser extent when used to coat plates, was observed to enhance biofilm formation for all of the clinical isolates tested herein (Table 1). Interestingly, analysis of staphylococcal biofilms by CLSM, also demonstrated that the biofilm phenotype was altered in the presence of human plasma, however changes in phenotype were strain dependent. For $S$. aureus MRSA3, the addition of plasma significantly enhanced biomass accumulation, whereas for $S$. aureus UAMS-1 the effect of plasma on biofilm formation seemed to be related to morphology, appearing more dense and compact compared to biofilms grown in only media (Figure 1A-B). Although coating of plates with $20 \%$ plasma $\mathrm{v} / \mathrm{v}$ was previously reported to be optimal for promoting biofilm formation on glass coverslips, we observed that coating had a minimal effect on biofilm formation by the clinical isolates even at concentrations $>5 \% \mathrm{v} / \mathrm{v}$ [19]. In contrast to these studies, and consistent with recent studies described in Chen et al., supplementation of media with plasma between $10-25 \% \mathrm{v} / \mathrm{v}$ was observed to be a more optimal biofilm growth condition, significantly enhancing biofilm formation compared to biofilms grown under non-supplemented conditions or in wells coated with plasma at similar concentrations (Table 1) [18]. Notably, the effect of plasma on biofilm formation was isolate-dependent, with methicillinresistant isolates appearing more responsive to plasma than the methicillin-susceptible isolate, UAMS-1 (Table 2).

The observed variability of biofilm formation in response to plasma among the $S$. aureus isolates is not surprising, and likely indicates differences in genetic backgrounds and consequently in the binding affinity to plasma components, such as fibrinogen and fibronectin [20-22]. Indeed, as the coating of surfaces with plasma is thought to provide surface attachments, the differences in gene repertoire as well as expression can in part explain these observed differences. Importantly, the observation that supplementing media with plasma, rather than coating the surface, had a greater effect on biofilm formation suggests that the components of plasma may not only serve to facilitate attachment as previously thought, but may also impart changes to bacteria making them better suited for biofilm growth. In support of this, SEM analysis of biofilms grown with media supplemented with plasma demonstrated significant changes in the cell morphology of individual bacterial cells within 
Table $1 \mathrm{~S}$. aureus biofilm formation is more enhanced when plasma is part of the growth medium, compared to coating plates with plasma prior to biofilm formation

\begin{tabular}{ccccc}
\hline Strain & $\begin{array}{c}\text { Percent } \\
\text { plasma }\end{array}$ & $\begin{array}{c}\text { Plasma } \\
\text { coated } \\
\text { OD570 } \\
\text { (mean + SD) }\end{array}$ & $\begin{array}{c}\text { Plasma in } \\
\text { medium } \\
\text { OD570 }\end{array}$ & P-value \\
(mean + SD) & \\
\hline MSSA UAMS-1 & 0 & $0.61 \pm 0.34$ & $0.87 \pm 0.31$ & \\
& 1 & $0.81 \pm 0.41$ & $1.63 \pm 0.48$ & 0.15 \\
MRSA 1 & 5 & $0.56 \pm 0.33$ & $1.4 \pm 0.58$ & 0.17 \\
& 10 & $0.25 \pm 0.08$ & $2.4 \pm 0.46$ & 0.01 \\
& 25 & $0.3 \pm 0.2$ & $1.95 \pm 0.58$ & 0.02 \\
& 50 & $0.32 \pm 0.17$ & $0.83 \pm 0.76$ & 0.22 \\
& 0 & $0.36 \pm 0.13$ & $0.38 \pm 0.18$ & \\
& 1 & $0.28 \pm 0.06$ & $0.77 \pm 0.26$ & 0.06 \\
& 5 & $0.67 \pm 0.47$ & $1.08 \pm 0.49$ & 0.22 \\
& 10 & $0.56 \pm 0.44$ & $1.44 \pm 0.33$ & 0.03 \\
& 25 & $0.58 \pm 0.27$ & $1.22 \pm 0.3$ & 0.08 \\
50 & $0.38 \pm 0.21$ & $0.67 \pm 0.56$ & 0.33
\end{tabular}

MRSA 2

$\begin{array}{cccc}0 & 0.38+0.13 & 0.6 \pm 0.19 & \\ 1 & 0.57+0.02 & 2.26+0.17 & 0.04 \\ 5 & 0.79+0.47 & 2.37+0.1 & 0.04 \\ 10 & 0.7+0.58 & 2.82+0.04 & 0.03 \\ 25 & 0.67+0.49 & 2.47+0.6 & 0.04 \\ 50 & 0.5+0.25 & 1.3+0.99 & 0.24\end{array}$

MRSA 3

$\begin{array}{cccc}0 & 0.58+0.31 & 0.53 \pm 0.14 & \\ 1 & 0.5+0.07 & 2.46+0.57 & 0.04 \\ 5 & 0.93+0.69 & 2.26+0.71 & 0.11 \\ 10 & 0.63+0.16 & 2.18+0.68 & 0.04 \\ 25 & 0.53+0.51 & 2.5+0.37 & 0.02 \\ 50 & 0.36+0.16 & 1.84+1.0 & 0.14\end{array}$

*96-well plates were coated with plasma for 24 hours, washed then biofilm was formed.

${ }^{\ddagger}$ Plasma coated compared to plasma in the growth medium. P-values generated via One-way ANOVA with a Dunnett's post hoc test.

biofilms, appearing as coccobacillus-like with a thicker, more heterogeneous appearing cell wall (Figure 1C-D). These changes to morphology, and likely to other properties of the biofilm, highlight the multiple effects that plasma can have in addition to the observed increases in biomass.

Although the effects of plasma have been previously reported, it is not completely understood how plasma enhances staphylococcal biofilm formation $[7,18,19]$. Staphylococci possess a number of surface expressed adhesins known as MSCRAMMs that facilitate attachment to host matrix molecules and are important for biofilm formation [5,6]. As these ligands are responsible for mediating attachment to surfaces, through interactions with host matrix components, we evaluated the effect of plasma on the expression of seven MSCRAMMs, including laminin binding protein (eno), encoding elastin binding protein (ebps), fibrinogen binding protein $(f i b)$, clumping factor $\mathrm{A} / \mathrm{B}(\mathrm{clfa} / \mathrm{clfb})$, and fibronectin binding protein $\mathrm{A} / \mathrm{B}(f b n A / f b n B)$ following exposure to plasma. In response to plasma, significant changes in MSCRAMM gene expression were observed for all clinical isolates tested (Table 3). The effect of plasma on MSCRAMM gene expression was both isolate- and time-dependent. Of the genes evaluated, expression of the fibrinogen and fibronectin binding protein genes were most responsive to plasma exposure (Table 3).

The transition from planktonic to surface-attached growth results in significant changes in gene expression that may promote the biofilm mode of growth. Consistent with our observations, gene expression of MSCRAMMs during biofilm growth, including fnbA/B, clfa, ebps, and $f i b$, have also been shown to be significantly enhanced during biofilm growth [23]. However, in these studies the expression of MSCRAMMs was optimally enhanced between 12 and 24 hours of biofilm growth. In contrast, we observed significant expression of the various MSCRAMM genes ( $>3$ fold) after only 30 minutes following plasma exposure. This supports previous findings by Chen et al. demonstrating significant increases in biofilm biomass as early as six hours of growth compared to biofilms grown under normal conditions [18] and indicating that plasma enhanced biofilm formation may in part result from changes in gene expression of MSCRAMMs.

\section{Biofilms grown in the presence of plasma demonstrate increased tolerance to vancomycin in vitro}

Given the findings demonstrating the effects of plasma on bacterial gene expression and morphology, we next evaluated whether plasma augmentation of biofilms also had an effect on the susceptibilities of biofilms to antimicrobials using a well-described biofilm susceptibility assay [24]. In contrast to biofilms grown without plasma, biofilms grown in the presence of plasma demonstrated a significantly reduced susceptibility to vancomycin in vitro (Figure 2). Consistent with this, plasma augmented biofilms of a clinical methicillin resistant (MRSA3) and methicillin susceptible S. aureus (UAMS-1) isolate had greater numbers of viable bacteria, as determined by colony enumeration, following overnight exposure to vancomycin even at the highest concentrations tested compared to untreated controls (Figure 2A-B). In agreement with these results, SEM analysis of biofilms grown in the presence of plasma following exposure to vancomycin at similar 


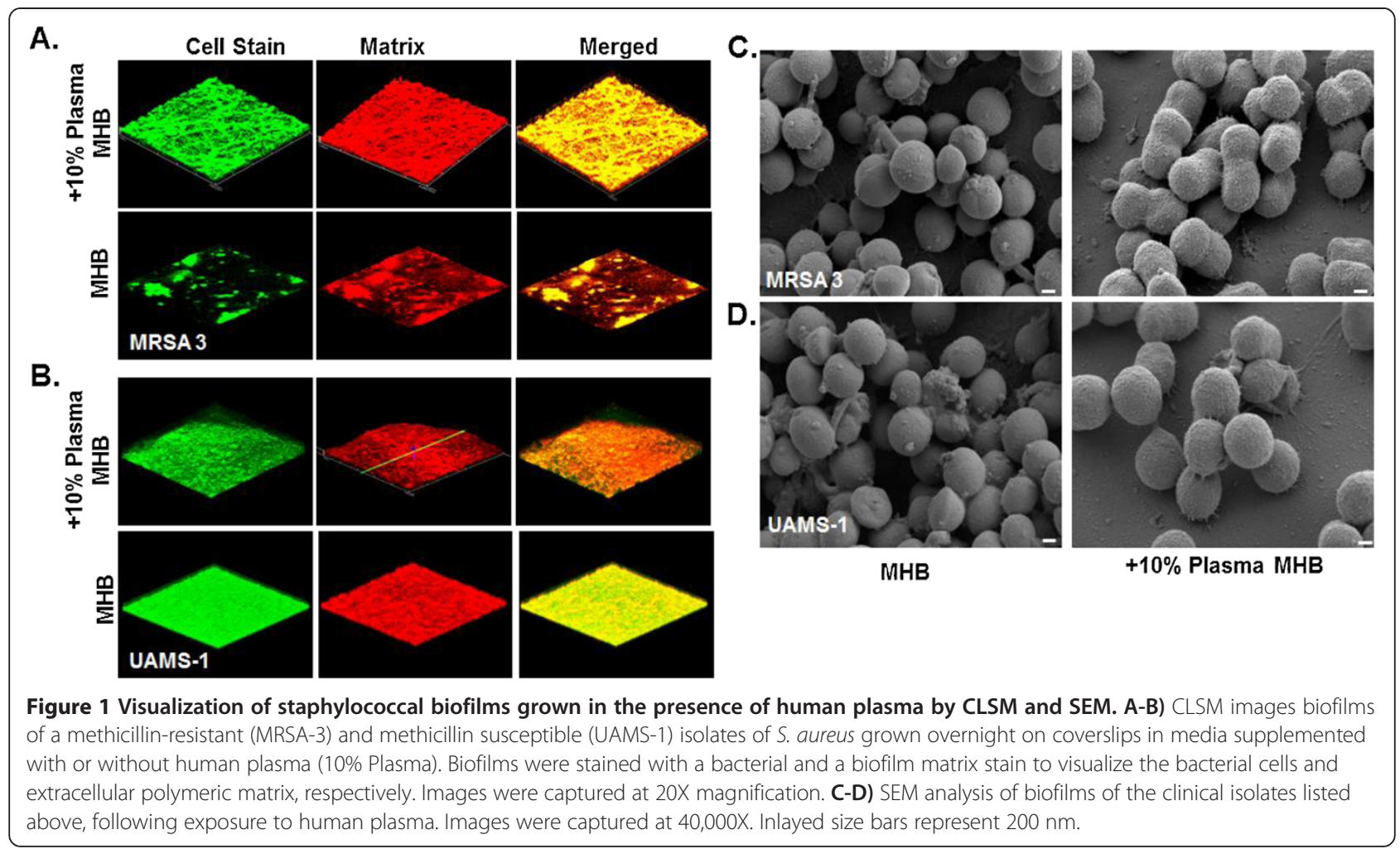

concentrations demonstrated no visual reduction in attached, viable bacteria (Figure 2C-D).

One possible explanation for the observed increased resistance to vancomycin, could involve selection for persister cells [25]. Recent data in Staphylococcus epidermidis suggests that the number of persister cells, bacteria within the biofilm having low metabolic activity and accounting for the population resistant to antimicrobials, increases at high bacterial densities [26]. Although we did not assess for the presence of persister cells, plasma-augmentation was observed to increase bacterial density and by extension may have increased the number of persister cells within the biofilm. Alternately, the inoculum effect may also explain why plasmaaugmented biofilms displayed reduced vancomycin susceptibility, as plasma-augmentation resulted in 3 log-units higher inoculum in the biofilms. Interestingly, vancomycin resistance in $S$. aureus has also been associated with increased cell wall thickness [27]. Given our observation by SEM that plasma treatment altered the $S$. aureus cell surface morphology (Figure 1, C-D), cell wall alteration may also have contributed to the overall reduced vancomycin susceptibility noted in this study. Nonetheless, the finding of reduced vancomycin susceptibility in plasma-exposed

Table 2 Increase in biofilm biomass measured by Crystal Violet method following incubation in plasma

\begin{tabular}{|c|c|c|c|c|c|c|c|c|}
\hline & \multicolumn{2}{|c|}{ UAMS-1 } & \multicolumn{2}{|c|}{ MRSA-1 } & \multicolumn{2}{|c|}{ MRSA-2 } & \multicolumn{2}{|c|}{ MRSA-3 } \\
\hline & $\mathrm{OD}_{570} \pm \mathrm{SD}$ & $\% \pm S D$ & $\mathrm{OD}_{570} \pm \mathrm{SD}$ & $\% \pm$ SDs & $O D_{570} \pm S D$ & $\% \pm$ SD & $\mathrm{OD}_{570} \pm \mathrm{SD}$ & $\% \pm S D$ \\
\hline $0 \%$ & $0.87 \pm 0.31$ & N/A & $0.38 \pm 0.18$ & N/A & $0.6 \pm 0.19$ & N/A & $0.53 \pm 0.14$ & N/A \\
\hline $1 \%$ & $1.63 \pm 0.48$ & $87 \pm 29$ & $0.77 \pm 0.26$ & $102 \pm 34$ & $2.26 \pm 0.17^{*}$ & $277 \pm 8 \uparrow$ & $2.46 \pm 0.57^{*}$ & $364 \pm 23 \uparrow$ \\
\hline $5 \%$ & $1.40 \pm 0.58$ & $61 \pm 41$ & $1.08 \pm 0.49^{*}$ & $189 \pm 45 \uparrow$ & $2.37 \pm 0.1^{*}$ & $295 \pm 4 \uparrow$ & $2.26 \pm 0.71^{*}$ & $326 \pm 31 \uparrow$ \\
\hline $10 \%$ & $2.40 \pm 0.46$ & $171 \pm 19$ & $1.44 \pm 0.33^{*}$ & $279 \pm 23 \uparrow$ & $2.82 \pm 0.04^{*}$ & $370 \pm 1 \uparrow$ & $2.18 \pm 0.68^{*}$ & $311 \pm 31 \uparrow$ \\
\hline $25 \%$ & $1.95 \pm 0.58$ & $124 \pm 30$ & $1.22 \pm 0.30^{*}$ & $221 \pm 25 \uparrow$ & $2.47 \pm 0.60^{*}$ & $317 \pm 24 \uparrow$ & $2.50 \pm 0.37^{*}$ & $368 \pm 15 \uparrow$ \\
\hline $50 \%$ & $0.83 \pm 0.76$ & $-5 \pm 92$ & $0.67 \pm 0.56$ & $76 \pm 84$ & $1.30 \pm 0.99$ & $117 \pm 76$ & $1.84 \pm 1.0$ & $249 \pm 54 \uparrow$ \\
\hline
\end{tabular}

*P $\leq 0.05$ vs. $0 \%$ plasma, One-way ANOVA with Dunnet's post hoc test.

$\uparrow \mathrm{P} \leq 0.05$ Percent increase in biofilm biomass (UAMS-1 vs. MRSA-1, MRSA-2, or MRSA-3) at comparable plasma percentages, One-way ANOVA with Dunnet's post hoc test.

Results are expressed as Mean OD570 \pm standard deviation and percent change from $0 \%$ plasma \pm SD. 
Table 3 10\% Plasma alters MSCRAMM gene expression in a strain dependent fashion

\begin{tabular}{|c|c|c|c|c|c|}
\hline \multirow[t]{2}{*}{ Strain } & \multirow[t]{2}{*}{ Gene } & \multicolumn{4}{|c|}{ Fold increase in gene expression* } \\
\hline & & $30 \mathrm{~min}$ & $60 \mathrm{~min}$ & $90 \mathrm{~min}$ & $120 \mathrm{~min}$ \\
\hline \multirow[t]{7}{*}{ UAMS-1 } & Laminin binding protein (Eno) & 1.62 & 2.06 & 2.76 & 3.39 \\
\hline & Encoding elastin binding protein (ebps) & 3.42 & 2.98 & 4.61 & 3.50 \\
\hline & Fibrinogen binding protein (fib) & 0.00 & 17.12 & 32.52 & 30.86 \\
\hline & Clumping factor $A$ (clfA) & 2.08 & 3.57 & 6.03 & 4.43 \\
\hline & Clumping factor $B$ (clfB) & 1.04 & 5.48 & 2.33 & 4.39 \\
\hline & Fibronectin binding protein (fbnA) & 11.22 & 4.28 & 5.25 & 1.96 \\
\hline & Fibronectin binding protein (fbnB) & 5.53 & 4.71 & 4.76 & 3.02 \\
\hline \multirow[t]{7}{*}{ MRSA-1 } & Laminin binding protein (Eno) & 1.51 & 2.15 & 2.85 & 2.51 \\
\hline & Encoding elastin binding protein (ebps) & 1.11 & 1.29 & 2.02 & 1.75 \\
\hline & Fibrinogen binding protein (fib) & 5.18 & 7.88 & 13.92 & 7.86 \\
\hline & Clumping factor $A$ (clfA) & 2.88 & 2.82 & 3.69 & 4.10 \\
\hline & Clumping factor $B$ (clfB) & 0.98 & 1.62 & 2.73 & 2.32 \\
\hline & Fibronectin binding protein (fbnA) & 32.23 & 46.84 & 30.30 & 2.79 \\
\hline & Fibronectin binding protein (fbnB) & 0.87 & 13.97 & 5.14 & 5.36 \\
\hline \multirow[t]{7}{*}{ MRSA-2 } & Laminin binding protein (Eno) & 1.06 & 3.53 & 3.83 & 3.63 \\
\hline & Encoding elastin binding protein (ebps) & 1.01 & 3.80 & 2.12 & 1.38 \\
\hline & Fibrinogen binding protein (fib) & 1.30 & 4.16 & 6.21 & 3.14 \\
\hline & Clumping factor $A$ (clfA) & 4.08 & 3.13 & 3.90 & 2.62 \\
\hline & Clumping factor $B$ (clfB) & 1.14 & 1.60 & 2.50 & 3.91 \\
\hline & Fibronectin binding protein (fbnA) & 2.59 & 7.14 & 4.89 & 2.00 \\
\hline & Fibronectin binding protein (fbnB) & 3.62 & 3.72 & 3.31 & 2.61 \\
\hline \multirow[t]{7}{*}{ MRSA-3 } & Laminin binding protein (Eno) & 1.31 & 1.86 & 3.96 & 2.95 \\
\hline & Encoding elastin binding protein (ebps) & 0.99 & 1.21 & 3.67 & 1.88 \\
\hline & Fibrinogen binding protein (fib) & 2.44 & 6.92 & 5.18 & 3.49 \\
\hline & Clumping factor $A$ (clfA) & 1.82 & 1.73 & 5.56 & 2.73 \\
\hline & Clumping factor $B$ (clfB) & 1.32 & 1.15 & 3.78 & 3.22 \\
\hline & Fibronectin binding protein (fbnA) & 2.57 & 2.08 & 4.26 & 5.30 \\
\hline & Fibronectin binding protein $(f b n B)$ & 2.60 & 2.35 & 3.53 & 3.75 \\
\hline
\end{tabular}

*A greater than or equal to 3 fold increase was statistically significant $(\mathrm{p}<0.05)$ compared to baseline gene expression $(\mathrm{t}=0)$, and are indicated in boldface, One-way ANOVA with a Dunnet's post hoc test.

biofilms has important implications for evaluating activity of antimicrobials and novel treatments against biofilms in vitro. Based on these studies, the inclusion of host factors may be necessary to fully evaluate susceptibility of biofilm-associated organisms under conditions that simulate the in vivo environment.

\section{Conclusion}

Most in vitro models used to study biofilms utilize incubation periods ranging from 12 to 48 hours, varying concentrations of ambient oxygen and carbon dioxide during incubation, varying incubation temperatures, and often omit potentially important host factors $[8,28,29]$. Consequently, although useful for high throughput analysis, in vitro models may not represent the true capacity of pathogens to form biofilms in vivo $[8,28,29]$. Thus there is a need for standardization in biofilm testing methods which is currently lacking [8].

While plasma has been previously demonstrated to increase biofilm formation [5-9,18,19], our study has extended this observation by examining the impact of plasma on several clinical isolates, demonstrating that host factors, including human plasma, can influence cell morphology and $S$. aureus gene expression, which may favor the biofilm phenotype.

These findings indicate a role for inclusion of host components into models evaluating biofilm formation as it would be more representative of in vivo conditions and may more accurately facilitate clinically relevant biofilm studies. 


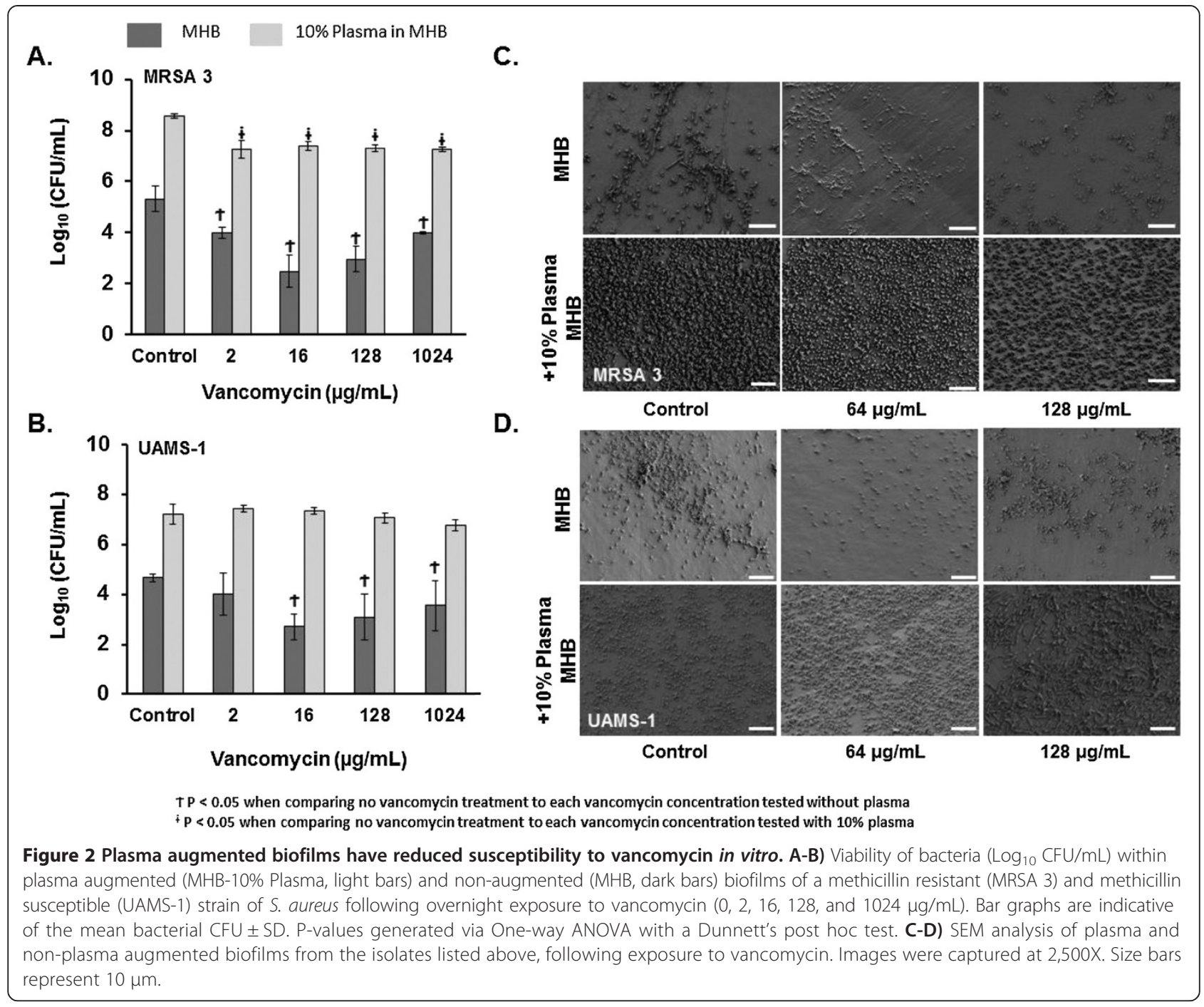

\section{Methods}

\section{Bacterial isolates and growth conditions}

Three clinical methicillin-resistant S. aureus (MRSA) isolates collected during clinical care from inpatients at our facility, previously demonstrated to be strong biofilmformers, were selected for study [30]. UAMS-1 (ATCC 49230), is a well-characterized, methicillin-susceptible osteomyelitis isolate of S. aureus [31]. The other isolates in this study were isolated from the following anatomic sites: bone (UAMS-1), nares (MRSA-1, MRSA-3), and the trachea (MRSA-2). The isolates also represent a variety of pulsed-field gel electrophoresis types: USA100 (MRSA-1), USA200 (UAMS-1), USA300 (MRSA-3), and USA800 (MRSA-2). Bacterial cultures were maintained at $-80^{\circ} \mathrm{C}$ and sub-cultured on sheep's blood agar plates (Remel, Lenexa, KS, USA) overnight at $37^{\circ} \mathrm{C}$ prior to each experimental assay. Bacteria were grown in Cation-Adjusted Mueller-Hinton Broth (MHB) (Becton Dickinson, Franklin
Lakes, NJ). UAMS-1 and MRSA-3 were selected for CLSM, SEM, and antimicrobial susceptibility testing.

\section{Antimicrobial agents and reagents}

Human plasma was purchased from the Biological Specialty Corporation (Colmar, PA). Plasma was filtered using $100 \mu \mathrm{m}$ cell isolators (BD Falcon, Franklin Lakes, NJ) and diluted in MHB at 1, 5, 10, 25, and 50\% (v/v). Vancomycin powder was purchased from Sigma-Aldrich (St Louis, MO).

\section{Biofilm formation in 96-well microtiter plates}

Biofilm formation was assessed by measuring the accumulation of biomass in sterile 96-well flat-bottom polystyrene plates (Costar, Corning Incorporated, Lowell MA) as previously described following $24 \mathrm{~h}$ incubation [30]. Briefly, $10 \mu \mathrm{L}$ of overnight bacterial suspensions $\left(\sim 10^{8} \mathrm{CFU}\right)$ were added to wells containing $190 \mu \mathrm{L}$ media supplemented 
with or wells coated with various concentrations of human plasma. Following $24 \mathrm{~h}$ incubation at $37^{\circ} \mathrm{C}$, wells were washed with PBS, stained with $0.1 \%$ crystal violet, and biomass was quantified by measuring the optical density at $570 \mathrm{~nm}\left(O D_{570}\right)$ of the supernatant following solubilization in ethanol. All experiments were performed in triplicate.

\section{Confocal laser scanning microscopy (CLSM)}

Biofilm formation by select clinical isolates was carried out on glass chamber slides (Thermo Scientific-Nunc, Rochester, NY) following $24 \mathrm{~h}$ exposure to media with or without $10 \%$ plasma by CLSM as previously described [19]. Briefly, following biofilm growth cells were washed with PBS and fixed with $4 \%$ formaldehyde. Biofilms were stained with a biofilm cell stain to visualize the extracellular polymeric matrix and bacterial cells according to the manufacturer's instructions (Molecular Probes, Eugene, OR). CLSM images were acquired using an Olympus FluoView 1000 Laser Scanning Confocal Microscope (Olympus America Inc., Melville, NY) under 20X magnifications using an argon laser at $488 \mathrm{~nm}$ and a $\mathrm{HeNe}-\mathrm{G}$ laser at $543 \mathrm{~nm}$. Image analysis/processing were via Olympus FluoView software. Images were acquired from at least three distinct regions on the slide and representative images were selected.

\section{Scanning electron microscopy (SEM)}

Biofilm formation was carried out for $24 \mathrm{~h}$ as described above in the presence or absence of $10 \%$ plasma, using the MBEC ${ }^{\mathrm{mm}}$ P\&G from Innovotech (Edmonton, Alberta, Canada). Following incubation, individual pegs were removed and fixed with $2 \%(\mathrm{w} / \mathrm{v})$ gluteraldehyde, $2 \%(\mathrm{w} / \mathrm{v})$ paraformaldehyde, $0.15 \mathrm{M}$ sodium cacodylate, $0.15 \%(\mathrm{w} / \mathrm{v})$ alcian blue. Pegs were rinsed thrice with $0.15 \mathrm{M}$ sodium cacodylate buffer, immersed in $1 \%(\mathrm{v} / \mathrm{v})$ osmium tetroxide in sodium cacodylate buffer and incubated for $1 \mathrm{hr}$ at room temperature. Pegs were rinsed thrice with distilled water followed by dehydration with an ascending series of ethanol (50\%, 75\%, 95\%, and 100\%). Samples were treated with hexamethyldisilizane for 5 minutes, re-submerged and allowed to evaporate at room temperature prior to mounting. Copper tape was used to secure the pegs to carbon tape on stubs to reduce charging artifact. Samples were sputter coated with gold and viewed with a Zeiss Sigma VP scanning transmission electron microscope.

\section{RNA isolation and quantitative real time reverse transcription PCR (qRT-PCR)}

Bacteria were grown to an $\mathrm{OD}_{600}$ of $0.2\left(\sim 10^{8}\right.$ bacteria/ml), washed with $1 \mathrm{X}$ PBS, and added to MHB media supplemented with $10 \%$ human plasma at a final concentration of $2 \times 10^{8} \mathrm{CFU} / \mathrm{mL}$. Bacteria were incubated in MHB with $10 \%(\mathrm{v} / \mathrm{v})$ plasma for $0,30,60,90$, and $120 \mathrm{~min}$ at $37^{\circ} \mathrm{C}$. Time points were chosen based on previous studies determined to be optimal for evaluating expression of MSCRAMMs following exposure to host components [32]. In addition, these time-points were chosen as the exopolysaccharide of the developing biofilm is visible in just 5 hours after inoculation and has the characteristics of a mature biofilm by 10 hours have been, and if plasma were to enhance biofilm formation via increased MSCRAMM expression, gene expression favoring biofilm formation would be induced in planktonic bacteria soon after exposure, prior to biofilm formation and maturation [33].

At the indicated timepoints, bacteria were harvested by centrifugation, washed, and RNA was isolated using an RNeasy Mini Kit (Qiagen, Valencia, CA) combined with Bacterial-RNA Protect (Qiagen) following the manufacturer's instructions. Bacteria were lysed by treating cells with lysostaphin $(200 \mu \mathrm{g} / \mathrm{ml})$ (Sigma-Aldrich, St. Louis, MO) for $30 \mathrm{~min}$ at $37^{\circ} \mathrm{C}$ (30). RNA was isolated, and reverse transcribed using the High Capacity cDNA reverse transcription kit (Life Technologies, Grand Island, NY), per the manufacturers' protocol. Quantitation of gene expression was via TaqMan (Life Technologies) methodology using the relative standard curve method. The gene specific PCR primers were developed with Primer Express software (Life Technologies) (Table 1). Gyrase B expression was the endogenous control. Realtime quantitative PCR reactions were performed with 1.5 ng of total RNA converted to cDNA template. PCR reactions consisted of the cDNA template, $1 \mathrm{X}$ Universal PCR Master Mix for Gene Expression (Life Technologies), gene specific primers $(900 \mathrm{nM})$ and probe $(250 \mathrm{nM})$ in a total volume of $20 \mu \mathrm{L}$. Standard curves consisted of tenfold dilutions of a positive control sample. PCR reactions were performed in triplicate and cycled in a $7900 \mathrm{HT}$ Sequence Detection System using standard protocols (Applied Biosystems, Grand Island, NY). Transcript levels were normalized to the internal control mRNA and foldregulation changes was calculated using $2^{-\Delta \Delta \mathrm{Ct}}$ method. Fold-gene expression equal or greater than 3 -fold was determined to be statistically significant $(p<0.05)$, following analysis using a 1-way ANOVA with a Dunnett's post hoc test comparing treatment groups to the control group.

\section{Viability of biofilm-derived bacteria after vancomycin exposure}

Biofilm formation was carried out as described above using the MBEC $C^{\mathrm{mm}} P \& G$. Briefly, bacteria were inoculated into wells containing either MHB with or without plasma (10\%), covered with a lid containing pegs for the attachment of the bacteria, and incubated at $37^{\circ} \mathrm{C}$ for $24 \mathrm{hr}$ with agitation. Following incubation, plate lids containing the pegs with the attached biofilms were washed with PBS, placed into 96 well plates containing 2 -fold serial dilutions of antibiotics diluted in MHB, and 
incubated overnight at $37^{\circ} \mathrm{C}$. To determine the viability of biofilm-derived bacteria following vancomycin exposure, MBEC plate lids were washed, placed into 96-well plates containing MHB, and biofilm-derived bacteria were detached from the pegs of lids by sonication for $5 \mathrm{~min}$. Plate lids with pegs were removed and replaced with a conventional microtiter plate lid. Bacterial viability was determined by plating serial dilutions on blood agar plates at 0 , and 6 hours post-exposure as per a previous study [34].

\section{Statistical analysis}

All experiments were performed in triplicate with a minimum of three technical replicates per individual experiment. The data sets were normally distributed, and for all quantitative studies a One-way ANOVA with a Dunnett's post hoc test was used to compare all treatment groups to the control group. P-values of $\leq 0.05$ were considered to be statistically significant. Statistical software utilized was SigmaStat ${ }^{\circ}$ Version 12.0.

\section{Competing interests}

The authors declare that they have neither financial nor non-financial competing interests.

\section{Authors' contributions}

APC, CJS, KSA and JCW conceived the study and participated in its design. APC, CJS, DRR, MES, and SKH conducted all experiments and collected data. APC, CKM, KSA, and JCW helped to draft the manuscript. APC and CJS performed the statistical analysis. All authors read and approved the final manuscript.

\section{Acknowledgements}

CSS is supported through a post-doctoral research fellowship through National Research Council. Portions of this work were presented at the 2013 IDSA Annual Meeting, San Francisco, CA, in October 2013. This work was supported by intramural funding from the Combat Casualty Research Program, Medical Research and Material Command to JCW.

\section{Author details}

${ }^{1}$ Department of Medicine, Infectious Disease Service, Brooke Army Medical Center, 3551 Roger Brooke Drive, JBSA Fort Sam Houston, TX 78234, USA.

${ }^{2}$ Extremity Trauma and Regenerative Medicine Task Area, United States Army Institute of Surgical Research, JBSA Fort Sam Houston, TX, USA.

Received: 11 February 2014 Accepted: 30 June 2014

Published: 17 July 2014

\section{References}

1. Costerton JW: Introduction to biofilm. Int J Antimicrob Agents 1999, 11:217-221. discussion 237-219.

2. Costerton JW, Stewart PS, Greenberg EP: Bacterial biofilms: a common cause of persistent infections. Science 1999, 284:1318-1322.

3. Hall-Stoodley L, Costerton JW, Stoodley P: Bacterial biofilms: from the natural environment to infectious diseases. Nat Rev Microbiol 2004, 2:95-108.

4. James GA, Swogger E, Wolcott R, Pulcini E, Secor P, Sestrich J, Costerton JW, Stewart PS: Biofilms in chronic wounds. Wound Repair Regen 2008, $16: 37-44$

5. Aly R, Levit S: Adherence of Staphylococcus aureus to squamous epithelium: role of fibronectin and teichoic acid. Rev Infect Dis 1987, 9(Suppl 4):S341-S350.

6. Vaudaux P, Pittet D, Haeberli A, Huggler E, Nydegger UE, Lew DP, Waldvogel FA: Host factors selectively increase staphylococcal adherence on inserted catheters: a role for fibronectin and fibrinogen or fibrin. $J$ Infect Dis 1989, 160:865-875.
7. Wagner $C$, Aytac $S$, Hansch GM: Biofilm growth on implants: bacteria prefer plasma coats. Int J Artif Organs 2011, 34:811-817.

8. Bjarnsholt T, Alhede M, Alhede M, Eickhardt-Sorensen SR, Moser C, Kuhl M, Jensen PO, Hoiby N: The in vivo biofilm. Trends Microbiol 2013, 21:466-474

9. Herrmann M, Vaudaux PE, Pittet D, Auckenthaler R, Lew PD, SchumacherPerdreau F, Peters G, Waldvogel FA: Fibronectin, fibrinogen, and laminin act as mediators of adherence of clinical staphylococcal isolates to foreign material. J Infect Dis 1988, 158:693-701.

10. Bridges M Jr, Morris D, Hall JR, Deitch EA: Effects of wound exudates on in vitro immune parameters. J Surg Res 1987, 43:133-138.

11. Espersen F, Wilkinson BJ, Gahrn-Hansen B, Thamdrup Rosdahl V, Clemmensen : Attachment of staphylococci to silicone catheters in vitro. APMIS 1990, 98:471-478.

12. Chang P, Aronson DL, Borenstein DG, Kessler CM: Coagulant proteins and thrombin generation in synovial fluid: a model for extravascular coagulation. Am J Hematol 1995, 50:79-83.

13. Henderson JM, Stein SF, Kutner M, Wiles MB, Ansley JD, Rudman D: Analysis of twenty-three plasma proteins in ascites. The depletion of fibrinogen and plasminogen. Ann Surg 1980, 192:738-742.

14. Hourigan LA, Linfoot JA, Chung KK, Dubick MA, Rivera RL, Jones JA, Salinas RD, Mann EA, Wade CE, Wolf SE, Baskin TW: Loss of protein, immunoglobulins, and electrolytes in exudates from negative pressure wound therapy. Nutr Clin Pract 2010, 25:510-516.

15. Igarashi Y, Skoner DP, Doyle WJ, White MV, Fireman P, Kaliner MA: Analysis of nasal secretions during experimental rhinovirus upper respiratory infections. J Allergy Clin Immunol 1993, 92:722-731.

16. Lehnhardt M, Jafari HJ, Druecke D, Steinstraesser L, Steinau HU, Klatte W, Schwake R, Homann HH: A qualitative and quantitative analysis of protein loss in human burn wounds. Burns 2005, 31:159-167.

17. Miller GJ, Howarth DJ, Attfield JC, Cooke CJ, Nanjee MN, Olszewski WL, Morrissey JH, Miller NE: Haemostatic factors in human peripheral afferent lymph. Thromb Haemost 2000, 83:427-432.

18. Chen P, Abercrombie JJ, Jeffrey NR, Leung KP: An improved medium for growing Staphylococcus aureus biofilm. J Microbiol Methods 2012, 90:115-118.

19. Walker JN, Horswill AR: A coverslip-based technique for evaluating Staphylococcus aureus biofilm formation on human plasma. Front Cell Infect Microbiol 2012, 2:39.

20. Elgalai I, Foster HA: Comparison of adhesion of wound isolates of Staphylococcus aureus to immobilized proteins. J Appl Microbiol 2003, 94:413-420.

21. Proctor RA, Mosher DF, Olbrantz PJ: Fibronectin binding to Staphylococcus aureus. J Biol Chem 1982, 257:14788-14794.

22. Que YA, Haefliger JA, Piroth L, Francois P, Widmer E, Entenza JM, Sinha B, Herrmann $M$, Francioli P, Vaudaux P, Moreillon P: Fibrinogen and fibronectin binding cooperate for valve infection and invasion in Staphylococcus aureus experimental endocarditis. J Exp Med 2005, 201:1627-1635.

23. Atshan SS, Shamsudin MN, Karunanidhi A, van Belkum A, Lung LT, Sekawi Z, Nathan JJ, Ling KH, Seng JS, Ali AM, Abduljaleel SA, Hamat RA: Quantitative PCR analysis of genes expressed during biofilm development of methicillin resistant Staphylococcus aureus (MRSA). Infect Genet Evol 2013, 18:106-112.

24. Coraca-Huber DC, Fille M, Hausdorfer J, Pfaller K, Nogler M: Evaluation of MBEC-HTP biofilm model for studies of implant associated infections. J Orthop Res 2012, 30:1176-1180.

25. Singh R, Ray P, Das A, Sharma M: Role of persisters and small-colony variants in antibiotic resistance of planktonic and biofilm-associated Staphylococcus aureus: an in vitro study. J Med Microbiol 2009, 58:1067-1073.

26. Qu Y, Daley AJ, Istivan TS, Rouch DA, Deighton MA: Densely adherent growth mode, rather than extracellular polymer substance matrix buildup ability, contributes to high resistance of Staphylococcus epidermidis biofilms to antibiotics. J Antimicrob Chemother 2010, 65:1405-1411.

27. Cui L, Ma X, Sato K, Okuma K, Tenover FC, Mamizuka EM, Gemmell CG, Kim MN, Ploy MC, El-Solh N, Ferraz V, Hiramatsu K, Ferraz V, Hiramatsu K: Cell wall thickening is a common feature of vancomycin resistance in Staphylococcus aureus. J Clin Microbiol 2003, 41:5-14.

28. Blanchette KA, Orihuela CJ: Future perspective on host-pathogen interactions during bacterial biofilm formation within the nasopharynx. Future Microbiol 2012, 7:227-239. 
29. Bjarnsholt $\mathrm{T}$ : The role of bacterial biofilms in chronic infections. APMIS Supp/ 2013, 136:1-51.

30. Sanchez CJ Jr, Mende K, Beckius ML, Akers KS, Romano DR, Wenke JC, Murray CK: Biofilm formation by clinical isolates and the implications in chronic infections. BMC Infect Dis 2013, 13:47.

31. Smeltzer MS, Thomas JR, Hickmon SG, Skinner RA, Nelson CL, Griffith D, Parr TR Jr, Evans RP: Characterization of a rabbit model of staphylococcal osteomyelitis. J Orthop Res 1997, 15:414-421.

32. Malachowa N, Whitney AR, Kobayashi SD, Sturdevant DE, Kennedy AD, Braughton KR, Shabb DW, Diep BA, Chambers HF, Otto M, DeLeo FR: Global changes in Staphylococcus aureus gene expression in human blood. PLoS One 2011, 6:e18617.

33. Harrison-Balestra C, Cazzaniga AL, Davis SC, Mertz PM: A wound-isolated Pseudomonas aeruginosa grows a biofilm in vitro within 10 hours and is visualized by light microscopy. Dermatol Surg 2003, 29:631-635.

34. Coraca-Huber DC, Fille M, Hausdorfer J, Pfaller K, Nogler M: Staphylococcus aureus biofilm formation and antibiotic susceptibility tests on polystyrene and metal surfaces. J Appl Microbiol 2012, 112:1235-1243.

doi:10.1186/1756-0500-7-457

Cite this article as: Cardile et al:: Human plasma enhances the

expression of Staphylococcal microbial surface components recognizing adhesive matrix molecules promoting biofilm formation and increases antimicrobial tolerance In Vitro. BMC Research Notes 2014 7:457.

\section{Submit your next manuscript to BioMed Central and take full advantage of:}

- Convenient online submission

- Thorough peer review

- No space constraints or color figure charges

- Immediate publication on acceptance

- Inclusion in PubMed, CAS, Scopus and Google Scholar

- Research which is freely available for redistribution 